Journal of Telenursing (JOTING)

Volume 3, Nomor 1, Juni 2021

e-ISSN: 2684-8988

p-ISSN: 2684-8996

DOI: https://doi.org/10.31539/joting.v3i1.2096

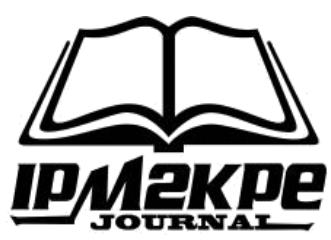

\title{
PERSEPSI PERAWAT TENTANG PERAN DALAM MENINGKATKAN KESELAMATAN PASIEN
}

\author{
Afeus Halawa ${ }^{1}$, Setiawan ${ }^{2}$, Bustami Syam ${ }^{3}$ \\ Universitas Sumatera Utara ${ }^{1,2,3}$ \\ afeushalawa@gmail.com ${ }^{1}$
}

\begin{abstract}
ABSTRAK
Penelitian ini bertujuan untuk mengeksplorasi persepsi perawat pelaksana tentang peran dalam meningkatkan keselamatan pasien di Rumah Sakit Umum Deli Medan. Penelitian ini adalah penelitian kualitatif dengan metode Focus Group Discussion (FGD). Hasil penelitian ini mengungkap 4 tema terkait dengan persepsi perawat pelaksana tentang peran dalam melaksanakan pasien di Rumah Sakit Umum Deli Medan. Simpulan, empat tema persepsi perawat tentang peran dalam melaksanakan keselamatan pasien yaitu: 1) kejadian yang hampir menyebabkan bahaya bagi pasien; 2) peran dalam meningkatkan keselamatan pasien; 3) faktor pendukung pelaksanaan peran dalam meningkatkan keselamatan pasien; 4) faktor penghambat pelaksanaan peran dalam meningkatkan keselamatan pasien.
\end{abstract}

Kata Kunci: Keselamatan Pasien, Peran, Persepsi Perawat

\section{ABSTRACT}

This study explores the perceptions of nurses on the role in improving patient safety at the Deli Medan General Hospital. This research is qualitative research using the method of Focus Group Discussion (FGD). This study's results reveal four themes related to the nurse's perception of the role in carrying outpatients at the Deli Medan General Hospital. In conclusion, there are four themes of nurses' perceptions about the role in implementing patient safety, namely: 1) events that almost cause harm to patients; 2) role in improving patient safety; 3) supporting factors for the implementation of roles in improving patient safety; 4) factors inhibiting the implementation of the role in improving patient safety.

Keywords: Patient Safety, Role, Nurse Perception

\section{PENDAHULUAN}

Diperkirakan 1 dari 10 pasien yang dirawat inap mengalami bahaya. Di negara berpenghasilan menengah dan rendah diperkirakan 8\% kejadian buruk, 83\% kondisi potonsial cedera, dan 30\% mengakibatkan kematian. Sekitar 421 juta pasien yang dirawat inap di dunia, dimana sekitar 42,7 juta pasien mengalami kejadian buruk (World Health Organization, 2017). Adapun insiden keselamatan pasien di Amerika Latin diperkirakan $10 \%$ dari pasien rawat inap mengalami kejadian buruk, sedangkan di Chili berkisar 6,2\% dan 15,7\% mengalami insiden (Carlesi et al., 2017).

World Health Organization (2020) mencatat ada 134 juta kejadian buruk yang terjadi setiap tahun dan 2,6 juta kematian per tahun akibat dari pelayan yang tidak aman. 
Empat dari 10 pasien di ruang rawat inap dan rawat jalan mengalami cedera. Akibat dari insiden-insiden yang terjadi, menelan biaya sekitar 42 milliar per tahun. Kesalahan dalam pengobatan telah menghabiskan biaya yang besar yakni US \$42 miliar setiap tahun di dunia, \$3,5 miliar di Amerika Serikat. Bahaya atau kematian yang menimpa pasien telah berlangsung selama 60 tahun yang lalu (Donaldson et al., 2017). Sedangkan di Korea, berdasarkan laporan diperoleh dari 5.744.566 pasien yang dirawat inap 9,2\% diantaranya mengalami cidera, 7,4\% meninggal dunia akibat dari kesalahan (Jang et al., 2017).

Berbagai penelitian telah dilakukan untuk mencegah kejadian buruk di rumah sakit. Komunikasi merupakan kunci utama dalam menyampaikan pesan dari pemberi pesan kepada penerima pesan. Komunikasi antara perawat dan pasien akan menentukan terciptanya suatu hubungan yang terbuka. Hubungan yang baik akan berdampak dalam keberhasilan rencana atau tindakan-tindakan yang diberikan pada pasien. semakin baik komunikasi makasemakin tinggi tingkat kepuasan dan keselamatan pasien (Alshammari et al., 2019).

Banyak pasien yang mengalami kerugian baik fisik maupun materi yang bersumber dari buruknya komunikasi tenaga medis selama berada di fasilitas pelayanan kesehatan.Untuk mencegah kejadian yang buruk tersebut, maka dilakukan sebuah penelitian intervensi yakni dengan penerapan metode SBAR. Metode ini terbukti telah meningkatkan komunikasi efektif yang pada akhirnya berdampak positif bagi keselamatan pasien (Burgener, 2020).

Komunikasi yang efektif diantara perawat dan dokter menjadi faktor utama dalam keberhasilan perawatan. Faktor-faktor yang mempengaruhi kesejangan komunikasi yakni kesiapan kerja perawat, lingkungan kerja, dan atribut dokter (Pattabi et al., 2018). Penelitian yang dilakukan di Belgia dengan melibatkan 688 pasien, 16,7\% diantaranya mengalami cedera akibat dari pengangkutan, dan 3,9\% mengalami cidera akibat perawatan. Hal ini disebabkan oleh adanya kesalahan dalam operasional dan komunikasi yang tidak efektif di antara petugas kesehatan (Lyphout et al., 2018).

Kolaborasi merupakan media yang menjembatani tercapainya tujuan bersama dalam merawat pasien. Kolaborasi perawat dan dokter serta kolaborasi perawat dan perawat telah terbukti memberikan hubungan signifikan dalam keselamatan pasien, sehingga kolaborasi interdisiplin harus ditingkatkan untuk mencapai kualitas pelayanan dengan mutu yang baik (Ma et al., 2018). Rumah sakit perlu mencegah kejadian buruk untuk meningkatkan keselamatan pasien dengan meningkatkan keterlibatan perawat (Carthon et al., 2019). Perawat merupakan tenaga kesehatan terbanyak, oleh sebab itu peran perawat diperlukan dalam keberhasilan tindakan. Menurut Lee \& Doran (2017) hubungan yang baik diantara perawat akan menentukan kualitas kinerja yang pada akhirnya berdampak pada pasien. Untuk mencegah cedera yang diakibatkan oleh kesalahan dalam pemberian obat maka antara pemberi layanan harus meningkatkan interaksi yang baik (Monsees et al., 2017).

Menurut Sharp et al., (2019) peran perawat sangat besar dalam keberhasilan pelayanan khususnya keselamatan pasien, perawat harus memberikan perhatian penuh, mencari informasi kesehatan pasien untuk mendukung perencanaan tindakan. Eriksson et al., (2018) mengutarakan bahwa cara penyampaian informasi dan edukasi oleh perawat sangat bermanfaat bagi kesehatan pasien. Dalam menjalankan perannya, seorang perawat harus memiliki komitmen memberikan tindakan sesuai dengan prosedur dan ilmu yang dimilikinya. Komitmen profesional perawat secara signifikan dan positif berhubungan dengan keselamatan pasien (Al-Hamdan et al., 2017). 
Pasien dan keluaraga didorong untuk terlibat dalam pengambilan keputusan berhubungan dengan tindakan selama berada di rumh sakit, dan menyampaikan informasi dengan sejujur-jujurnya. Hwang et al., (2019) berdasarkan penelitiannya menyatakan bahwa selain petugas kesehatan pasien juga menjadi faktor pendukung dalam mencegah kejadian-kejadian yang sering terjadi selama proses perawatan berlangsung. Berdasarkan uraian di atas, maka peneliti tertarik untuk mengeksplorasi persepsi perawat tentang peran dalam meningkatkan keselamatan pasien di Rumah Sakit Umum Deli Medan. Penelitian terdahulu merupakan penelitian kuantitatif yang menerapkan suatu intervensi kemudian mengukur tingkat keberhasilannya, sedangkan penelitian ini mengeksplorasi persepsi perawat tentang apa yang mereka lakukan selama bertugas di ruangan untuk meningkatkan keselamatan pasien.

\section{METODE PENELITIAN}

Penelitian ini adalah penelitian kualitatif. Partisipan dalam penelitian ini adalah perawat pelaksana berjumlah 15 orang. Data dikumpulkan menggunakan focus group discussion (FGD) secara daring menggunakan aplikasi zoom. Data yang diperoleh dianalisis dengan menggunakan content analysis. Analisis data kualitatif dilakukan dengan content analysis dan kuantitatif dengan statistik deskritif sederhana.

Ada 10 tahapan content analysis, yaitu: 1) membaca dan memahami seluruh hasil transkrip dengan teliti; 2) mengidentifikasi pernyataan signifikan (PS) dari setiap teks yang telah ditranskripsikan; 3) membuat tabel pernyataan signifikan (PS); 4) mengidentifikasi pernyataan signifikan (PS) untuk memastikan tidak ada PS yang terlewatkan; 5) melakukan sorting dengan ascending mode; 6) melakukan pengkodean untuk setiap pernyataan signifikan (PS); 7) mengelompokkan koding yang sama dalam suatu kategori; 8) mengecek kembali kesesuaian penempatan pernyataan signifikan (PS) dibawah satu kategori; 9) mengelompokkan kategori yang sejenis; dan 10) menentukan tema dan sub tema.

\section{HASIL PENELITIAN}

Tabel. 1

Distribusi Data Demografi Berdasarkan Usia, Jenis Kelamin,

Tingkat Pendidikan dan Lama Bekerja $(n=15)$

\begin{tabular}{lcc}
\hline \multicolumn{1}{c}{ Karakteristik } & F & $(\%)$ \\
\hline Usia (Tahun) & & \\
\hline $21-25$ & 1 & 6,7 \\
$26-30$ & 5 & 33,3 \\
$>30$ & 9 & 60,0 \\
\hline Jenis Kelamin & & \\
\hline Laki-laki & 0 & 0 \\
Perempuan & 15 & 100 \\
\hline Tingkat Pendidikan & & \\
\hline D3 Keperawatan & 8 & 53,3 \\
S1 Keperawatan & 4 & 26,7 \\
Ners & 3 & 20,0 \\
\hline Lama Bekerja (Bulan) & & \\
\hline 24-36 & 2 & 13,3 \\
37-48 & 4 & 26,7 \\
$>48$ & 9 & 60,00 \\
\hline Jumlah & 15 & 100 \\
& & \\
\hline
\end{tabular}


Hasil penelitian yang diperoleh dari penyebaran kuesioner berupa gambaran karakteristik perawat pelaksana terdiri dari usia, jenis kelamin, pendidikan, lama bekerja. Berdasarkan tabel 4.1 diketahui bahwa dari 15 partisipan, sebagaian besar berusia $>30$ tahun yaitu $9(60,0 \%)$. Seluruh partisipan berjenis kelamin perempuan yaitu sebanyak 15 (100\%). Sebagian besar partisipan memiliki jenjang pendidikan D3 Keperawatan yaitu sebanyak $8(53,3 \%)$. Sebagaian besar partisipan sudah bekerja selama $>48$ bulan yaitu sebanyak $9(60,0 \%)$.

\section{Persepsi Perawat Tentang Peran dalam Meningkatkan Keselamatan Pasien di Rumah Sakit Umum Deli Medan}

Hasil penelitian diperoleh 4 tema terkait dengan persepsi perawat tentang peran dalam meningkatkan keselamatan pasien di Rumah Sakit Umum Deli Medan. Tema tersebut terdiri dari: 1) kejadian yang hampir menyebabkan bahaya bagi pasien; 2) peran dalam meningkatkan keselamatan pasien; 3) faktor pendukung pelaksanaan peran dalam meningkatkan keselamatan pasien; 4) faktor penghambat pelaksanaan peran dalam meningkatkan keselamatan pasien; dan 5) kebiasaan yang dilakukan untuk mencegah kejadian yang membahayakan pasien.

\section{Kejadian yang Hampir Menyebabkan Bahaya Bagi Pasien}

Partisipan menyatakan bahwa kejadian yang hampir menyebabkan bahaya bagi pasien diantaranya: 1) pelaksanaan cuci tangan 6 langkah dengan 5 moment belum optimal; 2) doble check dalam pemberian obat hight alert belum terlaksana dengan optimal; 3) pasien hampir jatuh. Hal ini dapat dilihat pada kutipan sebagai berikut:

"....masih banyak diantara perawat di ruangan tidak melakukan cuci tangan enam langkah pada setiap sebelum dan sesudah melakukan tindakan...." (P1. L25 - L26)

“...sering kali di ruangan kadang kami tidak melakukan doble check terutama pada pemberian higt alert...” (P2. L47-L48)

“...Waktu itu pasien yang kita batasi ativitasnya nah... pernah pasien hampir mau jatuh karena pasien tersebut jalan ke kamar mandi untuk buang air katanya ..." (P3. L107-L108)

\section{Peran dalam Meningkatkan Keselamatan Pasien}

Partisipan menyatakan bahwa kejadian peran dalam meningkatkan keselamatan pasien diantaranya: 1) educator; 2) advocator; 3) evaluator. Hal ini dapat dilihat pada kutipan sebagai berikut:

“...menjadi seorang pemberi edukasi kepada pasien dan keluarga eee... menyampaikan informasi tentang kesehatan dan apa yang harus dilakukan pasien..." (P4. L122-123)

"...kita melindungi pasien dari kejadian-kejadian seperti kesalahan dalam pemberian obat, nah..oleh karena itu kita harus melakukan doble check...." (P5. L130-131)

“...setelah kita menyampaikan informasi atau mengajakarkan sesuatu kepada pasien dan keluarga kita harus mengevaluasinya kembali...”

(P7. L 144-145) 


\section{Faktor Pendukung Pelaksanaan Peran dalam Meningkatkan Keselamatan Pasien}

Partisipan menyatakan bahwa yang menjadi faktor pendukung dalam melaksanakan keselamatan pasien yaitu: 1) kepala ruangan selalu mengingatkan bawahan agar selalu menerapkan sasaran keselamatan pasien dalam setiap melakukan tindakan; dan 2) sudah menerapkan sasaran keselamatan pasien berdasarkan pada SNARS. Pernyataan partisipan dapat dilihat pada kutipan di bawah ini:

“...kepala ruangan selalu mengingatkan kita saat operan bahwasanya kalau eee... umpamanya ada pasien harus jelas operannya selalu berpedoman pada aturan akreditasi dengan menerapkan sasaran keselamatan pasien..." (P11. L269 - L271)

“...Rumah Sakit Umum Deli Medan sudah terakreditasi dan sudah menerapkan sasaran keselamatan pasien seperti yang dilaksnakan pada waktu akreditasi... (P14. L275 - L277)

\section{Faktor Penghambat Pelaksanaan Peran dalam Meningkatkan Keselamatan Pasien}

Partisipan menyatakan bahwa yang menjadi penghambat dalam melaksanakan keselamatan pasien adalah: 1) banyak tugas di ruangan; 2) jumlah perawat tidak sebanding dengan jumlah pasien; 3) pasien tidak kooperatif. Pernyataan partisipan dapat dilihat pada kutipan di bawah ini:

“...banyak tugas yang dikerjakan, kadang-kadang tugas tersebut tidak ada kaitannya dengan asuhan keperawatan...” (P14. L139 - L140)

"...perawat yang bertugas setiap hari sedikit tidak sebanding dengan jumlah pasien yang membutuhkan pelayanan di ruangan...”(P5. L190 L191)

“...yang menjadi penghambat juga yaitu pasien itu sendiri, eee... pasien tidak kooperatif ketika kita mengedukasi atau memberikan informasi..." (P10. L125-126)

\section{PEMBAHASAN}

Keselamatan pasien merupakan fokus utama dalam pemberian asuhan. Namun dalam pelaksanaannya banyak hal-hal yang membuat pelayanan tidak terlaksana secara optimal, baik dari faktor yang bersumber dari profesi keperawatan sendiri maupun dari pasien dan keluarga yang merupakan faktor pendukung keberhasilan dari suatu rencana ataupun implementasi perawatan.

Berdasarkan hasil penelitian diketahui bahwa perawat pelaksana di Rumah Sakit Umum Deli Medan mendeskripsikan bahwa pelaksanaan keselamatan pasien telah dilakukan di setiap ruangan, terlihat pada hasil wawancara yang dilakukan pada perawat pelaksana dengan menyatakan bahwa terdapat kejadian yang hampir menyebabkan bahaya bagi pasien, seperti: pelaksanaan cuci tangan 6 langkah dengan 5 moment belum optimal. Perawat (P1) menyatakan bahwa banyak perawat yang belum patuh pada kebersihan tangan enam langkah pada lima momen cuci tangan.

Salah satu sasaran keselamatan pasien adalah dikuranginya risiko terkait pelayanan kesehatan, hal ini dapat tercapai melalui penerapan kebersihan tangan enam langkah pada lima momen cuci tangan. Sejalan dengan studi Carter et al., (2018) yang mengungkapkan bahwa peran perawat dalam keselamatan pasien adalah mencegah infeksi pada pasien. Perawat merupakan kunci utama dalam mencegah hal-hal yang merugikan pasien. Momen cuci tangan harus diterapkan dengan disiplin oleh tenaga kesehatan. Kebersihan tangan dilakukan sebelum kontak dengan pasien, sebelum 
melakukan tindakan aseptik, setelah kontak dengan pasien, sesudah terkena cairan pasien, dan setelah kontak dengan area pasien. Hal ini dilakukan dengan metode handrub menggunakan larutan desifektan dan handwash menggunakan sabun.

Hasil penelitian juga menunjukkan bahwa double check ketika memberikan obat hight alert tidak dilakukan diantara perawat yang sedang bertugas. Pemeriksaan double checking didefinisikan sebagai verifikasi kebenaran dan kesesuaian komponen dari proses pemberian obat dengan menggunakan dua tenaga perawat dalam pengecekan sebelum obat diberikan. Double checking tepatnya sebagai prosedur dimana dua individu, sebaiknya dua praktisi secara terpisah memeriksa setiapkomponen dalam pemberian obat. Praktisi kedua harus memeriksa obat, dosis, perhitungan, cairan IV dan identitas pasien sebelum pemberian. Perlu disebutkan bahwa titik prosedur pemeriksaan adalah bahwa perawat diharapkan untuk menemukan kesamaan dalam informasi yang mereka kelola. Apabila seorang perawat menemukan hasil yang berbeda, dalam menyelesaikan perbedaan yang muncul harus dilakukan sebelum obat tersebut diberikan kepada pasien.

Perawat (P2) menyatakan bahwa dalam pemberian obat higt alert tidak dilakukan double check. Pernyataan ini menunjukkan kurangnya kolaborasi antara sesama perawat yang sedang bertugas. Kolaborasi merupakan sebuah peran yang harus dilaksanakan perawat untuk meningkatkan keselamatan pasien. Kolaborasi antara perawat akan menimbulkan hasil yang positif. Penelitian relevan dengan research Pedersen et al., (2018) kolaborasi dalam tim sangat penting dalam mencapai tujuan bersama. Koyama et al., (2020) mengemukakan double checking dilakukan oleh perawat, hal ini dilakukan untuk mencegah kesalahan dalam pemberian obat guna mencegah kejadian yang tidak diinginkan. Didukung oleh Chua et al., (2019) bahwa double checking merupakan hal yang harus dilaksanakan untuk mengurangi kesalahan pengobatan serta meningkatkan kualitas di rumah sakit.

Hasil penelitian ini mengungkapkan bahwa masih ada pasien yang hampir jatuh. Pasien jatuh di rumah sakit adalah masalah serius yang harus dicegah kejdiannya karena hal ini dapat menyebabkan cidera bahkan mengancam pasien. Perawat (P3) menyatakan bahwa masih ada pasien yang hampir jatuh ketika mau ke kamar mandi. Hal ini terjadi akibat kurangnya kerjasama antara perawat dengan pasien atau keluarga pasien dalam mencapai tujuan pelayanan yakni derajat kesehatan pasien. Selain perawat berkolaborasi dengan tim kesehatan lainnya, perawat harus berkolaborasi dengan pasien. Sesuai dengan pernyataan Stovall et al., (2020) bahwa, perawat dalam pemberian tindakan harus berkolaborasi dengan pasien dan keluarga, kolaborasi perawat dan keluarga pasien akan relatif lebih baik dalam mendapatkan perawatan yang optimal.

Banyak hal yang dapat dilaakukan oleh perawat untuk mencegah jatuh seperti melakukan reasesmen risiko jatuh serta mendokumentasikannya dalam catatan perkembangan pasien terintegrasi, mensosialisasi letak dan penggunaan bel, memasang palang tempat tidur, memastikan lantai tidak licin, pencahayaan yang adekuat di ruangan dan kamar mandi. Sejalan dengan penelitian Gutierres et al., (2018) yang menyatakan bahwaperawat memiliki tanggung jawab yang besar dalam memberikan pelayanan yang berkualitas, sehingga pasien aman dari bahaya.

Perawat memegang peran sangat penting dalam meningkatkan keselamatan pasien. Sesuai dengan pernyataan Andersson \& Hjelm (2017) bahwa perawat memainkan peran utama dalam keselamatan pasien dengan memastikan perawatan yang dilakukan setiap hari. Untuk meningkatkan kegiatan manajemen keselamatan pasien di rumah sakit, diperlukan pengembangan serta penerapan dari program intervensi 
keperawatan yang mengacu pada persepsi budaya keselamatan pasien, komitmen organisasi, dan pengalaman pendidikan keselamatan pasien (Im \& Park, 2018).

Perawat (P4) menyatakan bahwa salah satu peran perawat dalam keselamatan pasien adalah mengedukasi pasien dan keluarga terkait dengan kesehatan pasien. Pernyataan memiliki kesamaan dengan penelitian Jang \& Lee, (2017) bahwa, perawat memainkan perannya untuk mendorong pasien dan keluarga mencapai kesehatannya, mendidik pasien dan keluarga akan hal-hal yang dilakukan ataupun hal yang tidak boleh dilakukan selama menjalani perawatan. Dalam pelayanan kesehatan, keperawatan memiliki tugas yang harus dilaksanakan dalam memberikan asuhan perawatan yang berkualitas. Oleh karena itu penting untuk menunnjukkan keterlibatan perawat dalam upaya meningkatkan keselamatan pasien di ruang operasi (Gutierres et al., 2018).

Sementara itu menurut perawat (P5) peran perawat adalah menjadi pelindung pasien dari kejadian-kejadian yang merugikan pasien baik secara fisik maupun materi. Oleh sebab itu, dalam melakukan sebuah tindakan harus dilakukan sesuai dengan standar operasional prosedur yang ada. Penuturan perawat ini sesuai dengan penelitian Kennedy \& Kennedy (2018) yang menyatakan bahwa perawat memiliki peran sebagai advokasi bagi pasien, dimana perawat harus mendukung otonomi pasien mengenai keputusan dalam pengobatan atau tindakan, melindungi pasien dari kejadian-kejadian yang merugikan pasien, bertindak sebagi perantara antara dokter dengan pasien. Hal ini didukung oleh Kalaitzidis \& Jewell, (2020) yang mengungkapkan bahwa, peran advokasi perawat adalah melindungi pasien dari kebijakan, pemberian tindakan, serta menjadi penyambung lidah pasien untuk menyampaikan aspirasinya.

Tindakan yang diberikan memiliki risiko yang tinggi apabila tidak dilakukan sesuai dengan prosudur yang ada, kerja sama tim, dukungan pasien dan keluarga. Peran aktif keluarga dan pasien sebagai partner dalam pelayanan kesehatan untuk mencegah terjadinya bahaya disini sangat dibutuhkan, karena perawat tidak selalu berada disisi pasien. Keluarga menjadi juru bicara pasien ketika tidak dapat memberikan informasi kepada petugas kesehatan, keluarga menjadi penentu tindakan bahkan keberhasilan dari sebuah intervensi keperawatan.

Perawat (P7) menyatakan bahwa peran seorang perawat adalah mengevaluasi pemahaman pasien dan keluarga terhadap informasi yang telah disampaikan, sehingga tidak ada kesalahan informasi dan dapat ditindaklanjuti apabila pasien dan keluarga belum mengerti. Penelitian ini sejalan dengan penelitian yang dilakukan Rosa \& Sari (2018) yang menyatakan bahwa komunikasi menjadi penyebab utama kejadian-kejadian yang mencederai pasien di fasilitas pelayanan kesehatan. Kejadian-kejadian yang mencederai pasien erat hubungannya dengan mutu pelayanan, semakin tinggi kejadiankejadian yang merugikan pasien semakin rendah mutu pelayanan kesehatan. Untuk mencapai keselamatan pasien yang optimal, pemberi layanan harus didukung oleh kepala ruangan, dan juga sesama perawat pelaksana. Dukungan tersebut berupa perhatian, yaitu mengingatkan agar selalu menempelkan stiker risiko jatuh pada gelang identitas pasien, melakukan kebersihan tangan pada lima momen cuci tangan.

Menurut Fatonah \& Yustiawan (2020) untuk mencapai pelayanan yang berkualitas perlu dilakukan supervisi. Supervisi dilakukan oleh manejer keperawatan untuk mengawasi bahawahannya untuk memastikan terlaksananya pemberian asuhan keperawatan yang baik kepada pasien. Dipertegas oleh penelitian Mandriani et al., (2019) yang mengungkapkan bahwa, pekerjaan yang diawasi oleh pimpinan akan memberikan nilai positif dalam keselmatan pasien. Hubungan yang terjalin antara 
pimpinan dan bawahan akan memberikan dampak yang baik dalam penerapan budaya keselamatan pasien.

Menurut perawat (P11) faktor pendukung pelaksanaan peran yaitu kepala ruangan selalu mengingatkan perawat supaya melakukan serah terima sesuai dengan aturan akreditasi rumah sakit. Sedangkan menurut perawat (P14) menyatakan bahwa salah satu faktor pendukung pelaksanaan peran yaitu Rumah Sakit Umum Deli Medan telah terakreditasi dan menerapkan sasaran keselamatan pasien.

Hasil penelitian ini selaras dengan penelitian yang dilakukan Boamah, (2018) pemimpin dalam menjalankan manajemen harus mampu mendorong bawahan, mengawasi, dan mengevaluasi setiap pekerjaan, sehingga melalui tindakan ini dapat mencegah kejadian buruk dan meningkatkan mutu pelayanan. Didukung oleh Reis et al., (2017) manejer harus peduli dalam proses pemberian perawatan dengan cara mengawasi, sehingga menghasilkan sebuah suhan perawatan yang berkualitas. Seorang manajer harus mampu memimpin bawahannya dengan komunikasi yang baik, serta mendorong bawahan untuk melakukan praktik yang baik dan berkualitas. Menurut penelitian Udod et al., (2020) perawat manejer memegang peran utama dalam pelaksanaan asuhan keperawatan dengan mempromosikan serta mempertahankan strategi untuk mengurangi ketidakefektifan, meningkatkan koordinasi dengan bawahan agar dapat meningkatkan keselamatan pasien.

Perawat (P14) menyatakan bahwa banyak tugas yang harus dikerjakan di ruangan sehingga tidak melaksanakan peran dengan seoptimal mungkin. Untuk dapat mengupayakan penerapan sasaran keselamatan pasien dengan benar, partisipan kerap menghadapi beberapa hambatan yang datang dari diri partisipan sendiri dan dari aspek lain yang ikut berpengaruh dalam pencapaian penerapan sasaran keselamatan pasien. Adapun hambatan tersebut yaitu, seperti terkadang tidak konsisten memakaikan stiker resiko jatuh, menerapkan cuci tangan, double checking kebenaran obat high alert, mengkaji risiko jatuh pasien dan terkadang lupa memasang kembali gelang identitas pasien yang telah dilepas. Sedangkan menurut perawat (P5) jumlah perawat yang bertugas di ruangan tidak sebanding dengan jumlah pasien yang dirawat.

Kekurangan perawat merupaka suatu hal yang ada dalam diri perawat yang dapat menghambat penerapan keselamatan pasien dengan benar, beberapa partisipan menyatakan terkadang belum konsisten melakukan setiap upaya penerapan sasaran keselamatan pasien, misalnya dalam hal memakaikan stiker resiko jatuh, memasang kembali gelang identitas pasien setelah dilepas, juga dalam melakukan double checking obat high alert. Peningkatan beban kerja perawat akan mempengaruhi kualitas pelayanan atau asuhan keperawatan yang diberikan kepada pasien. Sejalan dengan penelitian Juvé-Udina et al., (2020) bahwa kekurangan tenaga perawat di ruang perawatan akan menimbulkan masalah yang serius.

Menurut perawat (P10) menyatakan bahwa faktor penghambat pelaksanaan peran yaitu pasien tidak kooperatif menerima edukasi yang disampaikan. Upaya penerapan sasaran keselamatan pasien memerlukan konsistensi dan kerjsama yang baik antar pihak yang terlibat dalam penerapan sasaran keselamatan pasien sehingga penerapan tersebut dapat diterapkan dengan benar. Menurut penelitian Neri et al., (2018) bahwa komunikasi antara perawat dan pasien merupakan kunci keberhasilan dalam keselamatan pasien. Komunikasi yang salah sering terjadi pada saat memberikan pesan secara lisan. Sementara keterlibatan pasien dalam proses pelayanan perawatan menentukan tingkat keberhasilan dari perawatan yang akan diberikan. Keterlibatan pasien diharapkan memberikan informasi tentang kesehatan atau kemajuan kesehatan 
setelah dirawat serta menerima informasi dari petugas kesehatan. Perawat harus melakukan pendekatan yang baik sehingga pasien terbuka dalam memberikan informasi sekalipun informasi tersebut adalah rahasia atau sensitif (Tobiano et al., 2018).

\section{SIMPULAN}

Ada 4 tema persepsi perawat tentang peran dalam melaksanakan keselamatan pasien yaitu kejadian yang hampir menyebabkan bahaya bagi pasien, peran dalam dalam meingkatkan keselamatan pasien, faktor pendukung pelaksanaan peran dalam meningkatkan keselamatan pasien dan faktor penghambat pelaksanaan peran dalam meningkatkan keselamatan pasien.

\section{SARAN}

Direkomendasikan kepada bidang keperawatan agar dapat meningkatkan keselamatan pasien dengan memberikan dukungan kepada perawat pelaksana melalui pembagian jadwal dinas dan tugas sesuai dengan beban kerja.

\section{DAFTAR PUSTAKA}

Al-Hamdan, Z. M., Dalky, H., \& Al-Ramadneh, J. (2017). Nurses' Professional Commitment and Its Effect on Patient Safety. Global Journal of Health Science, 10(1), 111. https://doi.org/10.5539/gjhs.v10n1p111

Alshammari, M., Duff, J., \& Guilhermino, M. (2019). Barriers to Nurse-Patient Communication in Saudi Arabia: An Integrative Review. BMC Nursing, 18(1), 110. https://doi.org/10.1186/s12912-019-0385-4

Andersson, F., \& Hjelm, K. (2017). Patient Safety in Nursing Homes in Sweden: Nurses' Views on Safety and Their Role. Journal of Health Services Research and Policy, 22(4), 204-210. https://doi.org/10.1177/1355819617691070

Boamah, S. (2018). Linking Nurses' Clinical Leadership to Patient Care Quality: The Role of Transformational Leadership and Workplace Empowerment. The Canadian Journal of Nursing Research = Revue Canadienne de Recherche En Sciences Infirmieres, 50(1), 9-19. https://doi.org/10.1177/0844562117732490

Burgener, A. M. (2020). Enhancing Communication to Improve Patient Safety and to Increase Patient Satisfaction. Health Care Manager, 39(3), 128-132. https://doi.org/10.1097/HCM.0000000000000298

Carlesi, K. C., Padilha, K. G., Toffoletto, M. C., Henriquez-Roldán, C., \& Juan, M. A. C. (2017). Ocorrência de Incidentes de Segurança do Paciente e Carga de Trabalho de Enfermagem. Revista Latino-Americana de Enfermagem, 25. https://doi.org/10.1590/1518-8345.1280.2841

Carter, E. J., Greendyke, W. G., Furuya, E. Y., Srinivasan, A., Shelley, A. N., Bothra, A., Saiman, L., \& Larson, E. L. (2018). Exploring the Nurses' Role in Antibiotic Stewardship: A Multisite Qualitative Study of Nurses and Infection Preventionists. American Journal of Infection Control, 46(5), 492-497. https://doi.org/10.1016/j.ajic.2017.12.016

Carthon, J. M. B., Hatfield, L., Plover, C., Dierkes, A., Davis, L., Hedgeland, T., Sanders, A. M., Visco, F., Holland, S., Ballinghoff, J., Del Guidice, M., \& Aiken, L. H. (2019). Association of Nurse Engagement and Nurse Staffing on Patient Safety. Journal of Nursing Care Quality, 34(1), 40-46. https://doi.org/10.1097/NCQ.0000000000000334

Chua, G., Lee, K., Peralta, G., \& Lim, J. (2019). Medication Safety: A Need to Relook 
at Double-Checking Medicines? Asia-Pacific Journal of Oncology Nursing, 6(3), 246-252. https://doi.org/10.4103/apjon.apjon_2_19

Donaldson, L. J., Kelley, E. T., Dhingra-Kumar, N., Kieny, M. P., \& Sheikh, A. (2017). Medication Without Harm: WHO's Third Global Patient Safety Challenge. The Lancet, 389(10080), 1680-1681. https://doi.org/10.1016/S0140-6736(17)31047-4

Eriksson, I., Lindblad, M., Möller, U., \& Gillsjö, C. (2018). Holistic Health Care: Patients' Experiences of Health Care Provided by an Advanced Practice Nurse. International Journal of Nursing Practice, 24(1), 1-7. https://doi.org/10.1111/ijn.12603

Fatonah, S., \& Yustiawan, T. (2020). Supervisi Kepala Ruangan Dalam Menigkatkan Budaya Keselamatan Pasien. Jurnal Keperawatan Silampari, 4(1), 151-161. https://doi.org/10.31539/jks.v4i1.1408

Gutierres, L. De S., Santos, J. L. G. Dos, Peiter, C. C., Menegon, F. H. A., Sebold, L. F., \& Erdmann, A. L. (2018). Good Practices for Patient Safety in The Operating Room: Nurses' Recommendations. Revista Brasileira de Enfermagem, 71(1), 2775-2782. https://doi.org/10.1590/0034-7167-2018-0449

Hwang, J. I., Kim, S. W., \& Chin, H. J. (2019). Patient Participation in Patient Safety and Its Relationships with Nurses' Patient-Centered Care Competency, Teamwork, and Safety Climate. Asian Nursing Research, 13(2), 130-136. https://doi.org/10.1016/j.anr.2019.03.001

Im, S., \& Park, M. J. (2018). The Effects of Patient Safety Culture Perception and Organizational Commitment on Patient Safety Management Activities in General Hospital Nurses.Journal of Digital Convergence, 16(6), 259-270. https://www.koreascience.or.kr/article/JAKO201819757620266.page

Jang, H.-E., Song, Y., \& Kang, H.-Y. (2017). Nurses' Perception of Patient Safety Culture and Safety Control in Patient Safety Management Activities. Journal of Korean Academy of Nursing Administration, 23(4), 450. https://doi.org/10.11111/jkana.2017.23.4.450

Jang, H., \& Lee, N. J. (2017). Patient Safety Competency and Educational Needs of Nursing Educators in South Korea. PLoS ONE, 12(9), 1-18. https://doi.org/10.1371/journal.pone.0183536

Juvé-Udina, M. E., González-Samartino, M., López-Jiménez, M. M., Planas-Canals, M., Rodríguez-Fernández, H., Batuecas Duelt, I. J., Tapia-Pérez, M., Pons Prats, M., Jiménez-Martínez, E., Barberà Llorca, M. À., Asensio-Flores, S., Berbis-Morelló, C., Zuriguel-Pérez, E., Delgado-Hito, P., Rey Luque, Ó., Zabalegui, A., Fabrellas, N., \& Adamuz, J. (2020). Acuity, Nurse Staffing and Workforce, Missed Care and Patient Outcomes: A Cluster-Unit-Level Descriptive Comparison. Journal of Nursing Management, 28(8), 2216-2229. https://doi.org/10.1111/jonm.13040

Kalaitzidis, E., \& Jewell, P. (2020). The Concept of Advocacy in Nursing: A Critical Analysis. The Health Care Manager, 39(2), 77-84. https://doi.org/10.1097/HCM.0000000000000292

Kennedy, G., \& Kennedy, F. (2018). Surgical Agency. Kennedys' Simulations for Negotiation Training, 25(1), 157-163. https://doi.org/10.4324/9781315251127-16

Khater, W. A., Akhu-Zaheya, L. M., Al-Mahasneh, S. I., \& Khater, R. (2015). Nurses' Perceptions of Patient Safety Culture in Jordanian hospitals. International Nursing Review, 62(1), 82-91. https://doi.org/10.1111/inr.12155

Koyama, A. K., Maddox, C. S. S., Li, L., Bucknall, T., Bucknall, T., \& Westbrook, J. I. (2020). Effectiveness of Double Checking to Reduce Medication Administration 
Errors: A Systematic Review. BMJ Quality and Safety, 29(7), 595-603. https://doi.org/10.1136/bmjqs-2019-009552

Lee, C. T. S., \& Doran, D. M. (2017). The Role of Interpersonal Relations in Healthcare Team Communication and Patient Safety: A Proposed Model of Interpersonal Process in Teamwork. The Canadian Journal of Nursing Research $=$ Revue Canadienne de Recherche En Sciences Infirmieres, 49(2), 75-93. https://doi.org/10.1177/0844562117699349

Lyphout, C., Bergs, J., Stockman, W., Deschilder, K., Duchatelet, C., Desruelles, D., \& Bronselaer, K. (2018). Patient Safety Incidents During Interhospital Transport of Patients: A Prospective Analysis. International Emergency Nursing, 36(July), 2226. https://doi.org/10.1016/j.ienj.2017.07.008

Ma, C., Park, S. H., \& Shang, J. (2018). Inter- and Intra-Disciplinary Collaboration and Patient Safety Outcomes in U.S. Acute Care Hospital Units: A Cross-Sectional Study.International Journal of Nursing Studies, 85(April), 1-6. https://doi.org/10.1016/j.ijnurstu.2018.05.001

Mandriani, E., Hardisman, H., \& Yetti, H. (2019). Analisis Dimensi Budaya Keselamatan Pasien Oleh Petugas Kesehatan di RSUD dr Rasidin Padang Tahun 2018. Jurnal Kesehatan Andalas, 8(1), 131. https://doi.org/10.25077/jka.v8i1.981

Monsees, E., Goldman, J., \& Popejoy, L. (2017). Staff Nurses as Antimicrobial Stewards: An Integrative Literature Review. American Journal of Infection Control, 45(8), 917-922. https://doi.org/10.1016/j.ajic.2017.03.009

Neri, R. A., Lestari, Y., \& Yetti, H. (2018). Analisis Pelaksanaan Sasaran Keselamatan Pasien Di Rawat Inap Rumah Sakit Umum Daerah Padang Pariaman. Jurnal Kesehatan Andalas, 7, 48. https://doi.org/10.25077/jka.v7i0.921

Pattabi, A., Kunjukunju, A., \& Hassan, H. (2018). Effective Communication Between Nurses and Doctors: Barriers as Perceived by Nurses. Journal of Nursing \& Care, 7(3), 2-6. https://doi.org/10.4172/2167-1168.1000455

Pedersen, A. H. M., Rasmussen, K., Grytnes, R., \& Nielsen, K. J. (2018). Collaboration and Patient Safety at an Emergency Department - a Qualitative Case Study. Journal of Health Organization and Management, 32(1), 25-38. https://doi.org/10.1108/JHOM-09-2016-0174

Reis, G. A. X. dos, Hayakawa, L. Y., Murassaki, A. C. Y., Matsuda, L. M., Gabriel, C. S., \& Oliveira, M. L. F. De. (2017). Nurse Manager Perceptions of Patient Safety Strategy Implementation TT - Implantacion de Las Estrategias de Seguridad Del Paciente: Percepciones de Enfermeros Gestores TT - Implantação Das Estratégias de Segurança do Paciente: Percepções de Enfermeiros . Texto \&amp; Contexto Enferm, 26(2), e00340016-e00340016. http://www.revenf.bvs.br/scielo.php?script=sci_arttext\&pid=S010407072017000200321

Rosa, E. M., \& Sari, K. N. (2018). Implementasi Komunikasi, Informasi dan Edukasi (Kie) Pada Perawat di Rumah Sakit PKU Muhammadiyah Temanggung. Berdikari: Jurnal Inovasi dan Penerapan Ipteks, 6(2), 227-231. https://doi.org/10.18196/bdr.6249

Sharp, L., Rannus, K., Olofsson, A., Kelly, D., \& Oldenmenger, W. H. (2019). Patient Safety Culture Among European Cancer Nurses-An Exploratory, CrossSectional Survey Comparing Data From Estonia, Germany, Netherlands, and United Kingdom. Journal of Advanced Nursing, 75(12), 3535-3543. https://doi.org/10.1111/jan.14177 
Stovall, M., Hansen, L., \& van Ryn, M. (2020). A Critical Review: Moral Injury in Nurses in the Aftermath of a Patient Safety Incident. Journal of Nursing Scholarship, 52(3), 320-328. https://doi.org/10.1111/jnu.12551

Tobiano, G., Bucknall, T., Sladdin, I., Whitty, J. A., \& Chaboyer, W. (2018). Patient Participation in Nursing Bedside Handover: A Systematic Mixed-Methods Review. International Journal of Nursing Studies, 77, 243-258. https://doi.org/10.1016/j.ijnurstu.2017.10.014

Udod, S. A., Duchscher, J. B., Goodridge, D., Rotter, T., McGrath, P., \& Hewitt, A. D. (2020). Nurse Managers Implementing the Lean Management System: A Qualitative Study in Western Canada. Journal of Nursing Management, 28(2), 221-228. https://doi.org/10.1111/jonm.12898

World Health Organization. (2017). Patient Safety: Making Health Care Safer. https://apps.who.int/iris/handle/10665/255507

World Health Organization. (2020). Health Worker Safety: A Priority for Patient Safety. https://www.who.int/campaigns/world-patient-safety-day/2020 